\title{
APLICAÇÃO DO RESÍDUO DA MINERAÇÃO DE BAUXITA EM CANA-DE-AÇÚCAR
}

\section{THE BAUXITE RESIDUE APPLIED IN SUGAR CANE}

\section{Adriano Gerim Ribeiro $^{1}$; João Antonio Galbiatti}

\author{
${ }^{1}$ Alcoa Alumínio. S.A.- Departamento de. Mineração, Poços de Caldas, MG. E-:mail: \\ adriano.ribeiro@alcoa.com.br \\ ${ }^{2}$ Faculdade de Ciências Agrárias e Veterinárias - Departamento de Engenharia Civil - \\ UNESP/Jaboticabal.E-mail: galbi@fcav.unesp.br
}

\section{RESUMO}

O experimento foi realizado em ambiente protegido com o objetivo de avaliar o efeito do resíduo da mineração de bauxita nos teores de macronutrientes e massa seca da cana-de-açúcar. Foram utilizados vasos de $10 \mathrm{~L}$ que receberam as seguintes doses de resíduo de bauxita: $0,28,56,84,112$ e $140 \mathrm{t} \mathrm{ha}^{-1}$, utilizando-se o clone de canade-açúcar SP92 4221. A incorporação do resíduo de bauxita no solo proporcionou aumento nos teores dos macronutrientes do solo, sendo que apenas para o enxofre doses acima de $83 \mathrm{t} \mathrm{ha}^{-1}$ proporcionaram reduções deste nutriente. Já para os teores de macronutrientes determinados na folha, doses acima de 70,$5 ; 125 ; 101$; $56 \mathrm{t} \mathrm{ha} \mathrm{h}^{-1}$ diminuíram os teores de nitrogênio, fósforo, potássio e enxofre, respectivamente. Para o cálcio e o magnésio, entretanto, a utilização do resíduo proporcionou a diminuição dos seus teores foliares. A dose do resíduo de bauxita na qual houve a maior produção de massa seca foi de $64 \mathrm{tha}^{-1}$.

Palavras-chave: Sacharum oficinarum. Condicionador de solo. Resíduo de bauxita.

\section{ABSTRACT}

The experiment was carried through in protecting environment with the objective to evaluate the effect of the bauxite residue in the macronutrients and dry mass concentrations in the sugar cane. Vases of $10 \mathrm{~L}$ had been used that they had received the following rates from bauxite residue: $0,28,56,84,112 \mathrm{e} 140 \mathrm{t} \mathrm{ha}^{-1}$, the used culture was the sugar cane (SP92 4221). The incorporation of the bauxite residue in the soil provided increase in the soil macronutrients concentration's, being that only for sulphur levels above of $83 \mathrm{t} \mathrm{ha}^{-1}$ had provided reductions of this nutrient. Already for the macronutrients concentration's determined in the leaf, levels above of 
70,$5 ; 125 ; 101 ; 56 \mathrm{t} \mathrm{ha}^{-1}$ diminished the nitrogen, phosphorum, potassium and sulphur concentration's, respectively. However, for calcium and magnesium the use of the residue provided the reduction of foliar concentration. The level of the bauxite residue in which had the biggest production of dry mass was of $64 \mathrm{tha}^{-1}$.

Keywords: Sacharum oficinarum. Soil conditioners. Bauxite residue.

\section{INTRODUÇÃO}

O resíduo alcalino do refino da bauxita, também denominado "lama vermelha" (red mud) é gerado do processo de extração de alumina da bauxita. A alumina hidratada ocorre na bauxita como gibsita, também chamada hidrargilita $\left(\mathrm{Al}_{2} \mathrm{O}_{3} .3 \mathrm{H}_{2} \mathrm{O}\right)$ e como boemita e diásporo, nas formas de monohidrato $\left(\mathrm{Al}_{2} \mathrm{O}_{3} \cdot \mathrm{H}_{2} \mathrm{O}\right)$. As principais impurezas encontradas nas bauxitas são os compostos de sílica, ferro e titânio. $\mathrm{O}$ comportamento destes compostos no beneficiamento da bauxita é de fundamental importância na obtenção de um produto final (alumina) de qualidade desejada, assim como, na composição do resíduo de bauxita. A composição química de cada resíduo de bauxita depende do minério que é utilizado e também do processo e condições industriais a que a bauxita é submetida para extração da alumina. Pode também ser afetado pela granulometria do minério de bauxita e da água utilizada no processo industrial (WONG, 1990).

Estudos têm demonstrado que o resíduo de bauxita tem grande potencial de uso como material na construção civil como é o caso da fabricação de agregados para utilização em concretos pré-moldados (SOUZA, 1989), na construção de estradas, (HARTLEY e THORPE, 1980) e como condicionador de solo em sistemas agrícolas (WARD, 1986).

Ferreira (2001), utilizando resíduo de bauxita com teor de cálcio e comportamento semelhante a corretivos de acidez, não identificou nenhum efeito tóxico nas plantas cultivadas, no entanto, o resíduo promoveu menor absorção de potássio, o que, segundo esse autor, deve estar associado a alta concentração de sódio no resíduo de bauxita, que competiria com o potássio.

Para se avaliar a adsorção de fósforo do resíduo de bauxita, Fortin e Karam (2001), demonstraram que a adsorção de fósforo tem relação direta com o teor de fósforo adicionado ao resíduo. Os mesmos ainda citaram que o aumento da absorção do nutriente pela planta, tem grande relação com o aumento do tempo de reação de adorção no solo. São escassos os trabalhos científicos que classificam o resíduo de bauxita como possível fonte de nutrientes para as plantas, que também, pode contribuir para a melhoria das propriedades físico-químicas do solo.

A cultura da cana-de-açúcar é adequada para o uso de resíduos, uma vez que não é de consumo direto, e desde que sejam adotados critérios que evitem a contaminação do solo e da planta, principalmente por metais pesados. Este trabalho teve como objetivo avaliar o efeito da incorporação, no solo, do resíduo de bauxita 
nos teores de macronutrientes do solo e das folhas, e na produção de massa seca da cultura da cana-de-açúcar.

\section{MATERIAL E MÉTODOS}

O experimento foi desenvolvido em ambiente protegido, localizado no setor de Plasticultura do Departamento de Engenharia Rural, da UNESP - Faculdade de Ciências Agrárias e Veterinárias - Campus de Jaboticabal, SP, cujas coordenadas geográficas são $21^{\circ} 15^{\prime} 15^{\prime}$ ' Latitude Sul, 48 $18^{\circ} 09^{\prime}$ ' Longitude Oeste e altitude em torno de $595 \mathrm{~m}$.

Utilizou-se amostras de solo oriundo de um Latossolo Vermelho distrófico de mata mesófila semidecidua residual, textura média, retiradas na camada de $0-20 \mathrm{~cm}$, cuja densidade foi de $1,3 \mathrm{~kg} \mathrm{dm}^{-3}$. A análise química foi realizada no Departamento de Solos e Adubos da Faculdade de Ciências Agrárias e Veterinárias - Campus de Jaboticabal (Tabela 1).

Tabela 1- Dados da análise química do solo.

\begin{tabular}{lc|lc}
\hline $\mathrm{pH}\left(\mathrm{CaCl}_{2} \mathrm{0,01 \textrm {M }}\right)$ & 4,7 & $\mathrm{Fe}\left(\mathrm{mg} \mathrm{dm}^{-3}\right)$ & 22 \\
$\mathrm{M} . \mathrm{O} .\left(\mathrm{g} \mathrm{dm}^{-3}\right)$ & 7 & $\mathrm{Mn}\left(\mathrm{mg} \mathrm{dm}^{-3}\right)$ & 11,2 \\
$\mathrm{P}\left(\mathrm{mg} \mathrm{dm}^{-3}\right)$ & 8 & $\mathrm{Cu}\left(\mathrm{mg} \mathrm{dm}^{-3}\right)$ & 0,3 \\
$\mathrm{~K}\left(\mathrm{mmol}_{\mathrm{c}} \mathrm{dm}^{-3}\right)$ & 1,1 & $\mathrm{Zn}\left(\mathrm{mg} \mathrm{dm}^{-3}\right)$ & 0,5 \\
$\mathrm{Ca}\left(\mathrm{mmol}_{\mathrm{c}} \mathrm{dm}^{-3}\right)$ & 6 & $\mathrm{~B}\left(\mathrm{mg} \mathrm{dm}^{-3}\right)$ & 0,11 \\
$\mathrm{Mg}\left(\mathrm{mmol}_{\mathrm{c}} \mathrm{dm}^{-3}\right)$ & 4 & $\mathrm{Na}\left(\mathrm{mg} \mathrm{dm}^{-3}\right)$ & 10 \\
$\mathrm{H}+\mathrm{Al}\left(\mathrm{mmol}_{\mathrm{c}} \mathrm{dm}^{-3}\right)$ & 16 & $\mathrm{~Pb}\left(\mathrm{mg} \mathrm{dm}^{-3}\right)$ & 0,3 \\
$\mathrm{SB}\left(\mathrm{mmol}_{\mathrm{c}} \mathrm{dm}^{-3}\right)$ & 11,1 & $\mathrm{Cd}\left(\mathrm{mg} \mathrm{dm}^{-3}\right)$ & 0 \\
$\mathrm{~T}\left(\mathrm{mmol}_{\mathrm{c}} \mathrm{dm}^{-3}\right)$ & 27,1 & $\mathrm{Ni}\left(\mathrm{mg} \mathrm{dm}^{-3}\right)$ & 3 \\
$\mathrm{Al}\left(\mathrm{mmol}_{\mathrm{c}} \mathrm{dm}^{-3}\right)$ & 1 & $\mathrm{Cr}\left(\mathrm{mg} \mathrm{dm}^{-3}\right)$ & 0 \\
$\mathrm{~V}(\%)$ & $\mathrm{S}-\mathrm{SO}_{4}\left(\mathrm{mg} \mathrm{dm}^{-3}\right)$ & 1 \\
\hline
\end{tabular}

O resíduo de bauxita foi seco, moído e peneirado (peneira ABNT 20). O material, depois de peneirado e homogeneizado, foi submetido à análise química conforme metodologia descrita pelo Lanarv (1988), tendo sido realizada no laboratório de química da ALCOA Alumínio S/A - MG (Tabela 2). 
Tabela 2 - Dados da análise química do resíduo de bauxita.

\begin{tabular}{lc|lc}
\hline $\mathrm{pH}\left(\mathrm{CaCl}_{2} 0,01 \mathrm{M}\right)$ & 11 & $\mathrm{Mn}\left(\mathrm{mg} \mathrm{kg}^{-1}\right)$ & 2100 \\
$\mathrm{~N}\left(\mathrm{~g} \mathrm{~kg}^{-1}\right)$ & 4 & $\mathrm{Cu}\left(\mathrm{mg} \mathrm{kg}^{-1}\right)$ & 4 \\
$\mathrm{P}\left(\mathrm{g} \mathrm{kg}^{-1}\right)$ & 0,001 & $\mathrm{Zn}\left(\mathrm{mg} \mathrm{kg}^{-1}\right)$ & 111 \\
$\mathrm{~K}\left(\mathrm{~g} \mathrm{~kg}^{-1}\right)$ & 11,4 & $\mathrm{~B}\left(\mathrm{mg} \mathrm{kg}^{-1}\right)$ & 490 \\
$\mathrm{Ca}\left(\mathrm{g} \mathrm{kg}^{-1}\right)$ & 17 & $\mathrm{~Pb}\left(\mathrm{mg} \mathrm{kg}^{-1}\right)$ & 183 \\
$\mathrm{Mg}\left(\mathrm{g} \mathrm{kg}^{-1}\right)$ & 1 & $\mathrm{Cd}\left(\mathrm{mg} \mathrm{kg}^{-1}\right)$ & 3 \\
$\mathrm{~S}-\mathrm{SO}_{4}\left(\mathrm{~g} \mathrm{~kg}^{-1}\right)$ & 0,8 & $\mathrm{Ni}\left(\mathrm{mg} \mathrm{kg}^{-1}\right)$ & 270 \\
$\mathrm{Fe}\left(\mathrm{g} \mathrm{kg}^{-1}\right)$ & 137 & $\mathrm{Cr}\left(\mathrm{mg} \mathrm{kg}^{-1}\right)$ & 3 \\
$\mathrm{Al}\left(\mathrm{g} \mathrm{kg}^{-1}\right)$ & 122 & $\mathrm{Na}\left(\mathrm{g} \mathrm{kg}^{-1}\right)$ & 50,1 \\
\hline
\end{tabular}

Em vasos de polietileno com capacidade para $10 \mathrm{~L}$ foram testadas 6 concentrações de resíduo de bauxita: testemunha (0), 2, 4, 6, 8 e $10 \%$ do volume do vaso, correspondendo a: testemunha (0), 28, 56, 84, 112 e $140 \mathrm{t} \mathrm{ha}^{-1}$ resíduo do processamento de bauxita, respectivamente, sendo que o cálculo para estimar a quantidade de resíduo em $\mathrm{t} \mathrm{ha}^{-1}$ considerou a camada de $0-20 \mathrm{~cm}$ do solo. A escolha das concentrações foi feita de acordo com ensaio preliminar, no qual foram utilizados volumes maiores de resíduo de bauxita $(0,10,20,30,40,50,60,70,80$ e $100 \%$ em vasos de $10 \mathrm{~L}$ ).

Para a instalação do experimento efetuou-se, primeiramente, a peneiração do solo para retirar todos os agregados maiores e resíduos grosseiros de material orgânico. Feito isso, misturou-se o solo e o resíduo da extração de bauxita, em sacos plásticos, em função dos tratamentos.

Depois do enchimento dos vasos, procedeu-se o plantio da cana-de-açúcar (SP 924221), onde foram utilizadas mudas provenientes de cultura de tecidos apresentando 3 plantas de cana-de-açúcar por muda, com $10 \mathrm{~cm}$ de altura cada. Foi estabelecido a relação de uma muda de cana-de-açúcar para cada vaso do experimento e o tempo de desenvolvimento da planta foi de 118 dias.

Foram realizadas irrigações diárias com base no método do tanque classe A (MONTERO et al. 1985) e no coeficiente da cultura para cálculo da quantidade de água de acordo com Doorenbos e Kasam (1994) citado por Fachini et al. (2004).

No final do experimento, foi coletada a folha diagnostica +3 das plantas e colocadas dentro de sacos plásticos, identificadas e levadas ao laboratório do Departamento de Engenharia Rural da Faculdade de Ciências Agrárias e Veterinárias, Campus de Jaboticabal. No laboratório as folhas foram lavadas com água de torneira e enxaguadas com água destilada. Folhas secas, murchas ou deterioradas foram excluídas. Após as lavagens, as folhas foram colocadas em saco de papel, secas em estufa de circulação forçada de ar a $60{ }^{\circ} \mathrm{C}$ durante 3 dias, e em seguida, trituradas em 
moinho do tipo Wiley, passadas em peneiras de malha 1,0 mm (20 mesh). No final da secagem e antes de ser triturado o material, a planta toda foi pesada para determinação da quantidade de matéria seca por vaso $\left(\mathrm{g}\right.$ vaso $\left.^{-1}\right)$. Para a análise de nutrientes $(\mathrm{N}, \mathrm{P}, \mathrm{K}, \mathrm{Ca}, \mathrm{Mg}$ e $\mathrm{S})$ na planta foi seguida metodologia descrita por Malavolta et al. (1997). Os resultados foram submetidos à análise de variância e de regressão entre as concentrações de resíduo de bauxita e de macronutrientes do solo, da planta e da massa seca da cana-de-açúcar, de acordo com os procedimentos do Statistical analysis system (SAS INSTITUTE, 1999).

\section{RESULTADOS E DISCUSSÕES}

\subsection{Nutrientes no Solo}

A aplicação de doses do resíduo de bauxita (zero a $140 \mathrm{t} \mathrm{ha}^{-1}$ ) elevou o valor de pH do solo de 4,43 para 6,73, descrevendo uma função linear (Figura 1a). A causa da elevação do $\mathrm{pH}$ está na alcalinidade do resíduo de bauxita, que é devida à adição de carbonato de cálcio feita em uma das etapas da industrialização, para a eliminação do fósforo, e à presença de hidroxilas $\left(\mathrm{OH}^{-}\right)$na soda caustica usada na extração do alumínio. Como o resíduo é rico em hidroxilas e carbonatos, estes reagirão com o $\mathrm{H}^{+}$ da solução do solo, diminuindo assim a acidez do solo. Ferreira (2001) utilizando resíduo de bauxita em solo, verificou mudanças semelhantes no comportamento do $\mathrm{pH}$, também devido à presença de hidroxilas que atuam na neutralização de íons $\mathrm{H}^{+}$. De acordo com o Raij et al. (1996) a acidez do solo com a aplicação crescente do resíduo de bauxita passou de um limite alto $(\mathrm{pH}$ de $4,4-5,0)$ para um limite muito baixo ( $\mathrm{pH}$ de 5,6-6,0). 


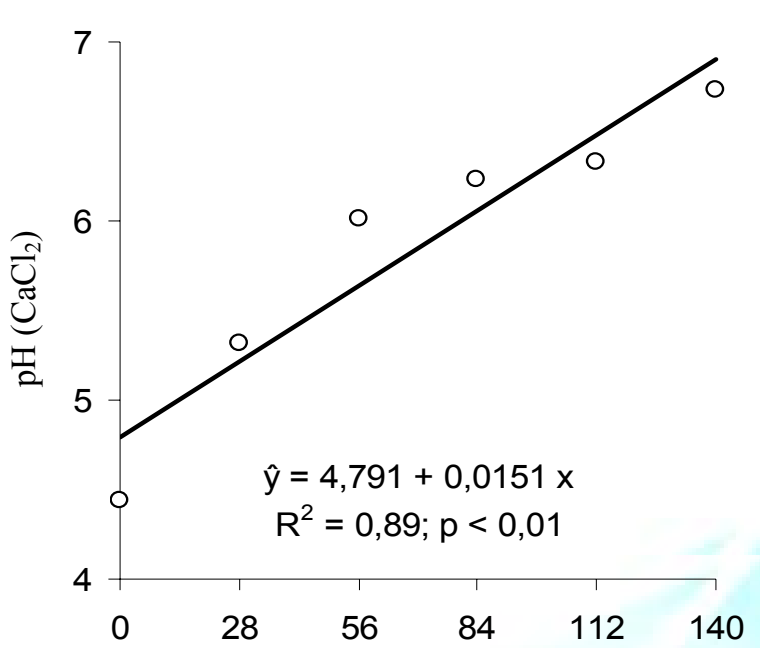

(a)

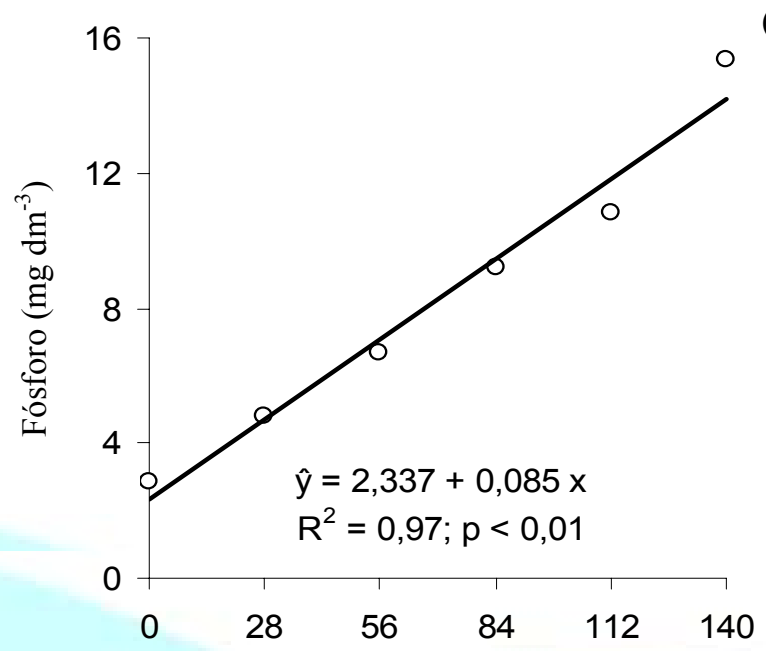

(b)

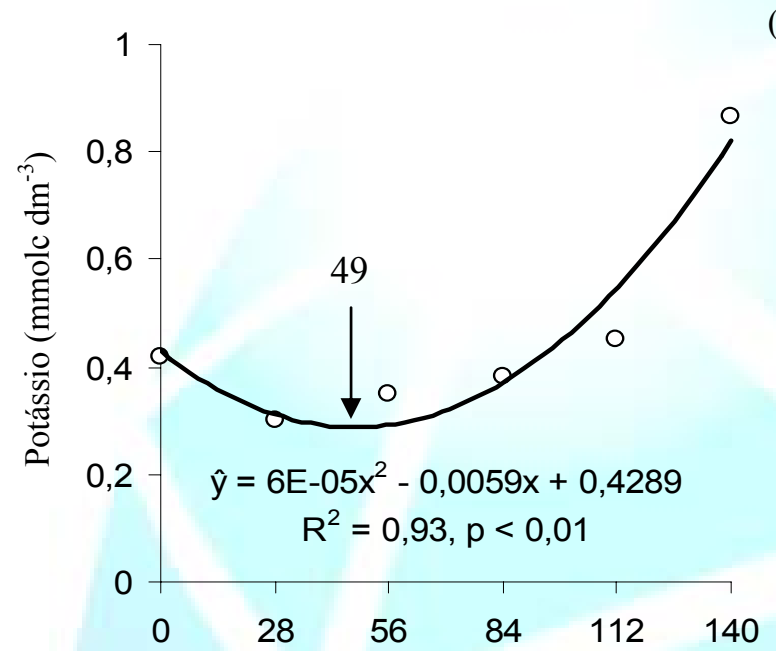

(c)
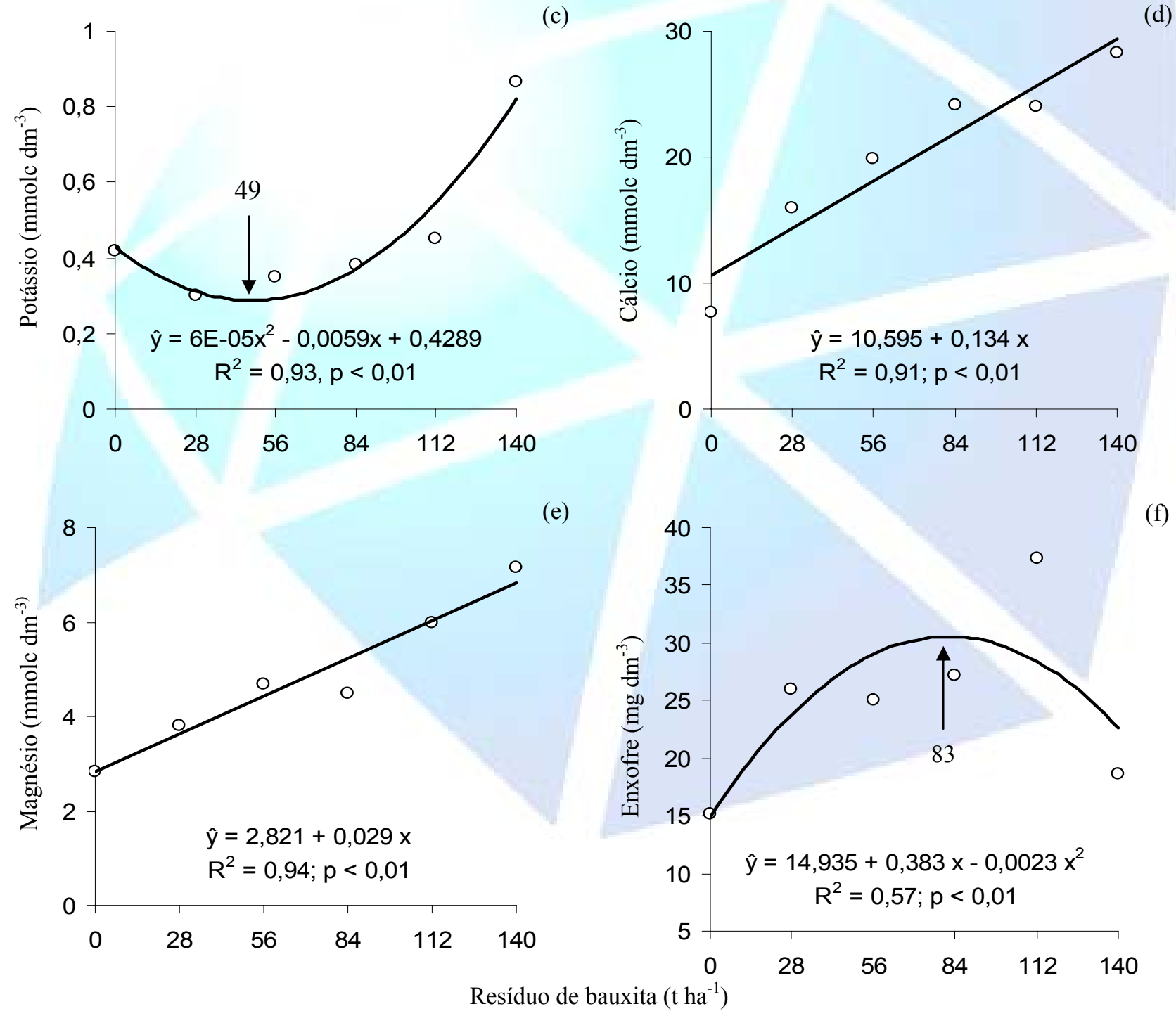

Figura 1. Regressões entre as doses de resíduo de bauxita incorporados ao solo e $\mathrm{pH}\left(\mathrm{CaCl}_{2}\right)$, teor de fósforo, potássio, cálcio, magnésio e enxofre determinados no solo. 
As concentrações de fósforo no resíduo de bauxita são baixos (Tabela 2) em função da formação de compostos insolúveis com o cálcio, entretanto, observou-se aumento linear do do mesmo no solo com o incremento do resíduo. Segundo Ferreira (2001), o aumento de fósforo no solo está relacionado com a elevação do $\mathrm{pH}$, causada pela adição do resíduo. Este aumento do $\mathrm{pH}$ faz com que o fósforo adsorvido nos colóides do solo passariam para a solução, tornando-se disponíveis para as plantas, sendo que a maior disponibilidade ocorre em $\mathrm{pH}$ ao redor de seis. Robertson et al. (1997), avaliando as concentrações de fósforo em solos que receberam resíduo de bauxita $\left(60 \mathrm{t} \mathrm{ha}^{-1}\right)$, também constataram aumento deste elemento no solo à medida que se aumentava a dose de resíduo de bauxita.

Todas as doses aqui testadas aumentaram significativamente as concentrações de fósforo no solo, quando comparadas com os valores encontrados para a testemunha. Resultados semelhantes foram encontrados por McPharlin et al. (1994) que, aplicando $0,60,120$ e $240 \mathrm{t} \mathrm{ha}^{-1}$ de resíduo de bauxita para avaliar a lixiviação do fósforo, observaram que o fósforo retido na camada de $0-15 \mathrm{~cm}$ do solo aumentou em 34\%. As concentrações de fósforo obtidas com a aplicação de resíduo de bauxita estão dentro dos limites considerados baixos $\left(6-12 \mathrm{mg} \mathrm{dm}^{-3}\right)$ por Raij et al. (1996), com exceção da aplicação de $140 \mathrm{tha}^{-1}$ que ficou na faixa considerada média (16-40 $\left.\mathrm{mg} \mathrm{dm}{ }^{-3}\right)$.

Para potássio observa-se que inicialmente houve uma redução em sua concentração no solo até a dose $49 \mathrm{t} \mathrm{ha}^{-1}$ de resíduo (Figura 1c) e, a partir deste valor, houve um aumento crescente nas concentrações de potássio, concordando com os resultados obtidos por Ward (1986). Umas das possibilidades para esse aumento, mesmo que baixo, das concentrações de potássio no solo está no aumento do $\mathrm{pH}$. Outra possibilidade, um pouco mais remota, já que a concentração de matéria orgânica no solo é baixa, seria o aumento da degradação da matéria orgânica. Com o aumento de $\mathrm{pH}$ haveria maior atividade microbiana, que conseqüentemente degradaria a matéria orgânica, liberando potássio para o solo (RAIJ, 1991).

As concentrações de potássio verificadas para a testemunha e as doses de 28 , 56,84 e $112 \mathrm{t} \mathrm{ha}^{-1}$ foram consideradas muito baixas $\left(0,0-0,7 \mathrm{mmol}_{\mathrm{c}} \mathrm{dm}^{-3}\right)$, já à aplicação no tratamento de $140 \mathrm{tha}^{-1}$ de resíduo de bauxita elevou as concentrações a um limite considerado baixo $\left(0,8-1,5 \mathrm{mmol}_{\mathrm{c}} \mathrm{dm}^{-3}\right)$, de acordo com Raij et al. (1996).

Os altos valores de cálcio encontrados no resíduo são devidos à adição de calcário $\left(\mathrm{CaCO}_{3}\right)$, no processo Bayer de extração da bauxita, interferindo em sua composição química. O uso de cal no processo Bayer visa promover o aumento da filtrabilidade da pasta, pela remoção do fósforo presente na bauxita, o que auxilia a filtração e recuperação da soda cáustica. (FERREIRA, 2001). Os compostos contendo cálcio acabam sendo enviados para o lago, seja em solução ou junto à lama que sai dos filtros. Logo, a adição do resíduo no solo proporcionou um incremento linear na concentração de cálcio (Figura 1d) do solo, e com a aplicação de $28 \mathrm{tha}^{-1}$ do resíduo as estas concentrações dobraram em relação à testemunha, passando de 8 para 16 $\mathrm{mmol}_{\mathrm{c}} \mathrm{dm}^{-3}$ (Figura 1d). Summers et al. (1996) também observaram aumento nas 
concentrações de cálcio com a aplicação de $40 \mathrm{t} \mathrm{ha}^{-1}$ do resíduo de bauxita. Todas as doses aplicadas elevaram os níveis de cálcio a um limite considerado alto $\left(>7 \mathrm{mmol}_{\mathrm{c}}\right.$ $\mathrm{dm}^{-3}$ ) (RAIJ et al., 1996).

A quantidade de magnésio presente na testemunha, $\left(2,8 \mathrm{mmol}_{\mathrm{c}} \mathrm{dm}^{-3}\right)$ é considerada baixa, contudo, com a aplicação do resíduo de bauxita esses níveis passaram para limites considerados médios $\left(5-8 \mathrm{mmol}_{\mathrm{c}} \mathrm{dm}^{-3}\right.$ ), (RAIJ et al., 1996). O aumento das doses do resíduo no solo promoveu um aumento linear na concentração de magnésio no solo (Figura 1e).

O resíduo de bauxita apresenta baixos teores de magnésio em sua composição, o que não poderia explicar os aumentos do elemento nos diferentes tratamentos. Assim, este aumento poderia ser devido à elevação de pH (Figura 1a). Outra possibilidade seria o deslocamento de magnésio em decorrência a grande quantidade de cálcio presente no solo. $\mathrm{O}$ cálcio em grande quantidade promoveria $\mathrm{o}$ deslocamento de magnésio dos colóides para a solução do solo, aumentando assim suas concentrações disponíveis a cada incremento do resíduo de bauxita. O maior aumento de magnésio (Figura 1e) no solo ocorreu com as doses de $112 \mathrm{e} 140 \mathrm{t} \mathrm{ha}^{-1}$, com valores de 6,00 e 7,16 $\mathrm{mmol}_{\mathrm{c}} \mathrm{dm}^{-3}$ de magnésio respectivamente. Ward (1986) também verificou a disponibilidade de elementos em solos que foram neutralizados com resíduos de bauxita, observando que houve aumento nas concentrações de magnésio presentes no solo.

A aplicação do resíduo de bauxita proporcionou aumento da concentração de enxofre no solo até a dose de $83 \mathrm{t} \mathrm{ha}^{-1}$, na qual ocorreu a maior concentração do elemento no solo, sendo de $37,33 \mathrm{mg} \mathrm{dm}^{-3}$ de enxofre (Figura 1f). Quando não houve aplicação de resíduo de bauxita, a concentração foi de $15,16 \mathrm{mg} \mathrm{dm}^{-3}$ de enxofre, tendo sido esta a menor concentração de enxofre no solo. O enxofre é absorvido pelas plantas na forma do ânion $\mathrm{SO}^{-2}{ }_{4} \mathrm{e}$ em muitos solos, esse ânion não é retido no solo sendo facilmente lixiviado. Um fator muito importante na adsorção do enxofre nos colóides do solo é o $\mathrm{pH}$, pois quanto maior for o $\mathrm{pH}$ menor será a adsorção (RAIJ, 1991). Segundo esse autor o aumento da disponibilidade do nutriente se dá com o aumento das doses testadas, visto que a cada incremento de dose de resíduo de bauxita há aumento significativo nos valores de $\mathrm{pH}$ fazendo com que a quantidade de enxofre presente na solução do solo se eleve. Percebe-se que acima de $83 \mathrm{t} \mathrm{ha}^{-1}$ do resíduo as concentrações de enxofre no solo diminuíram, o que pode ser atribuído ao aumento do enxofre da solução fazendo com que o elemento se desloque para a fase sólida, ou seja, algum enxofre passe da solução do solo para a fase sólida, sendo por ele adsorvido (COELHO e VERLENGIA, 1988), explicando assim a diminuição dos teores de enxofre em função do aumento das doses do resíduo de bauxita. De acordo com (RAIJ et al., 1996), em todas as doses do resíduo de bauxita testadas, inclusive o tratamento testemunha, as concentrações de enxofre estão no limite considerado alto $\left(>10 \mathrm{mg} \mathrm{dm}^{-3}\right)$. 


\subsection{Nutrientes nas Folhas}

De acordo com a regressão, doses acima de 70,5 $\mathrm{t} \mathrm{ha}^{-1}$ de resíduo foram prejudiciais para o acúmulo de nitrogênio na planta (Figura 2a). O resíduo de bauxita apresenta nitrogênio em sua composição, sendo que o aumento deste elemento na planta também pode estar associado á microrganismos livres existentes no solo. $\mathrm{O}$ aumento do $\mathrm{pH}$ do solo estimula o desenvolvimento microbiano, o qual degrada a matéria orgânica do solo, disponibilizando nitrogênio as plantas, semelhante ao que ocorre na reforma do canavial (NOBILE, 2005). Assim, nos solos com vegetação nativa, onde o teor de nitrogênio é mantido em baixo nível, a fixação assimbiótica pode ter uma importante contribuição na acumulação de nitrogênio no solo. As condições que favorecem a fixação assimbiótica de nitrogênio são: alto conteúdo de cálcio e matéria orgânica rica em carbono (COELHO e VERLENGIA, 1988). Todos os teores de nitrogênio encontrados nas diferentes doses testadas estão de acordo com os teores mínimos característicos na parte colhida de cana-de-açúcar $\left(1,30 \mathrm{~g} \mathrm{~kg}^{-1}\right)$, segundo Raij (1991). 


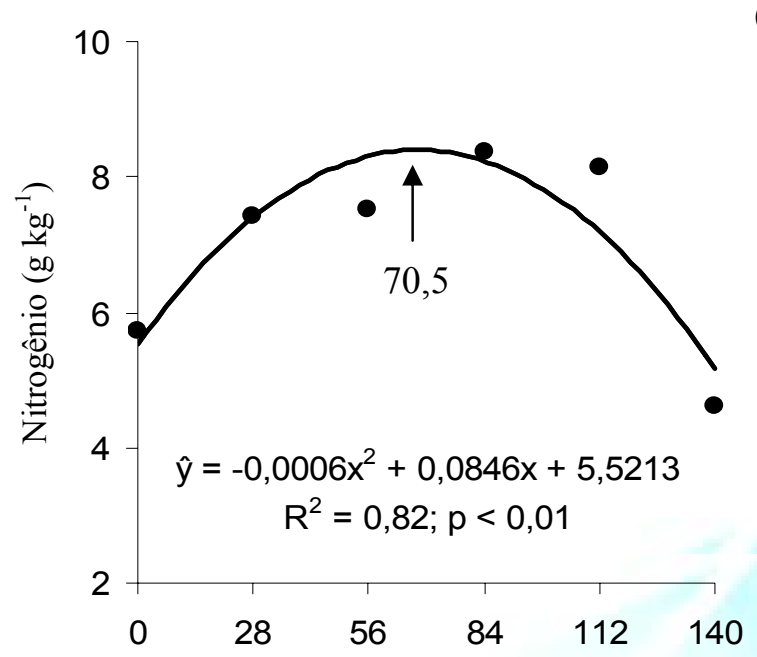

(a)

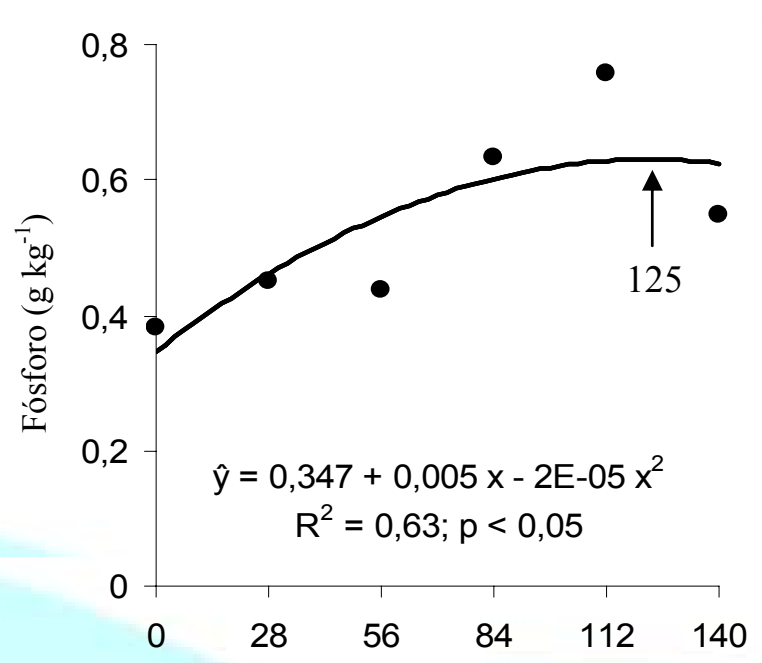

(b)

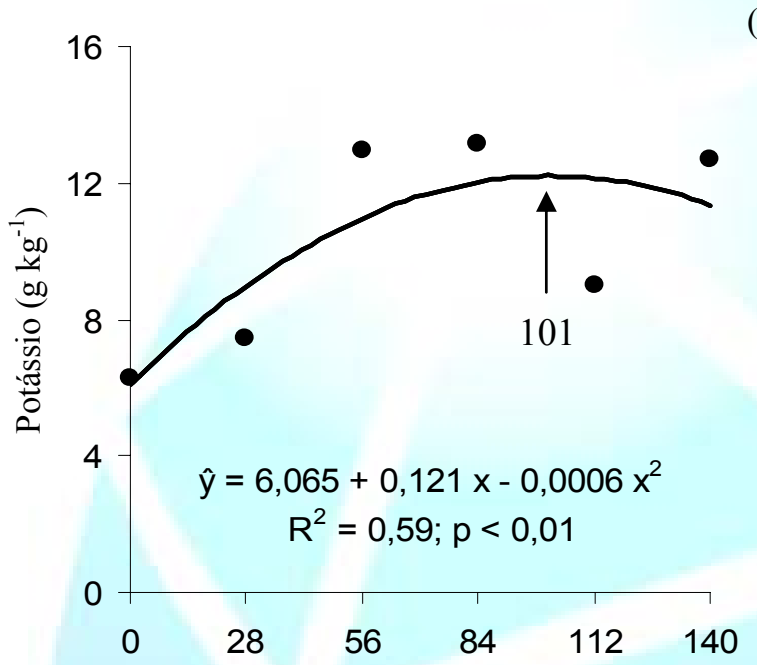

(c)
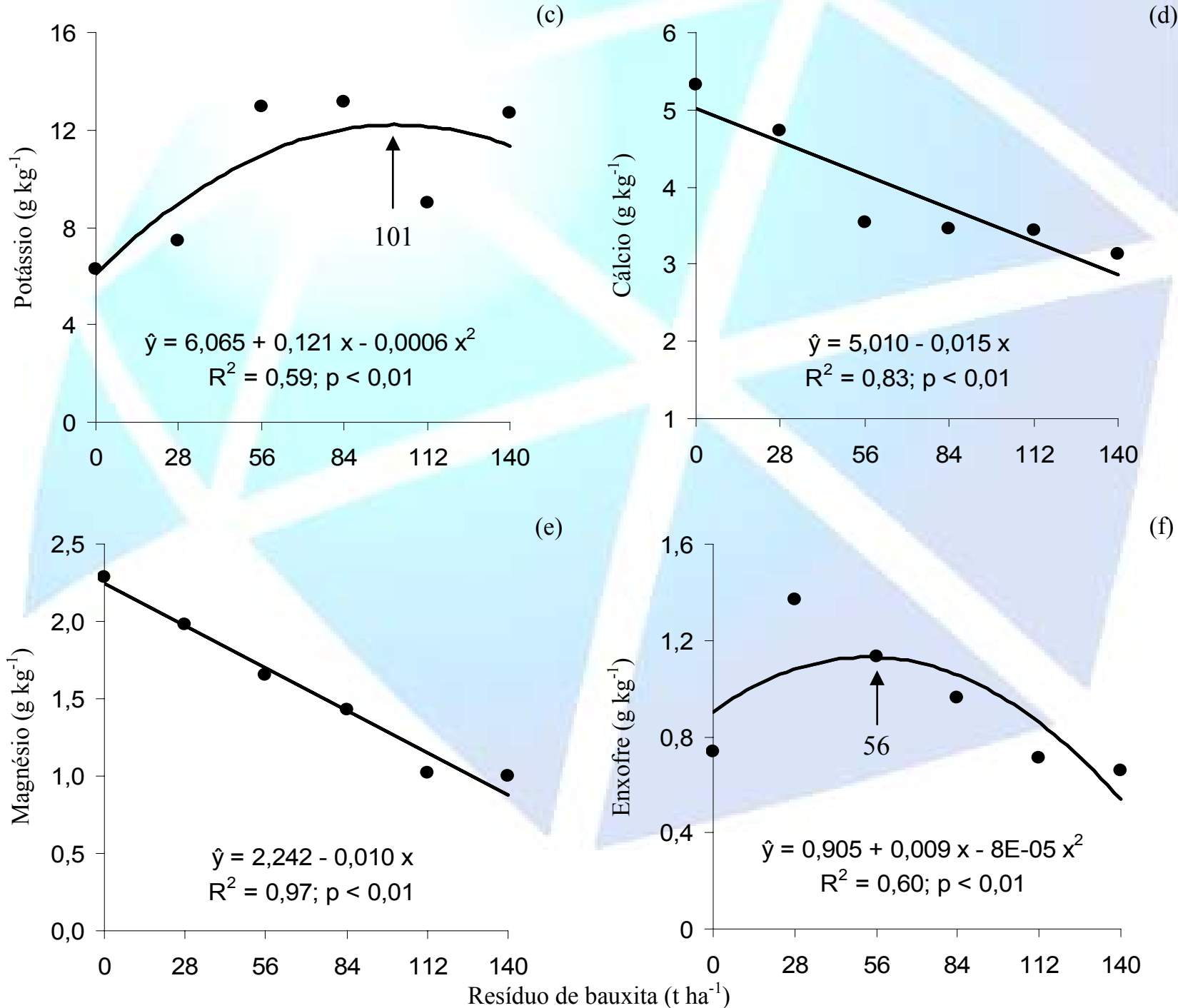

(e)

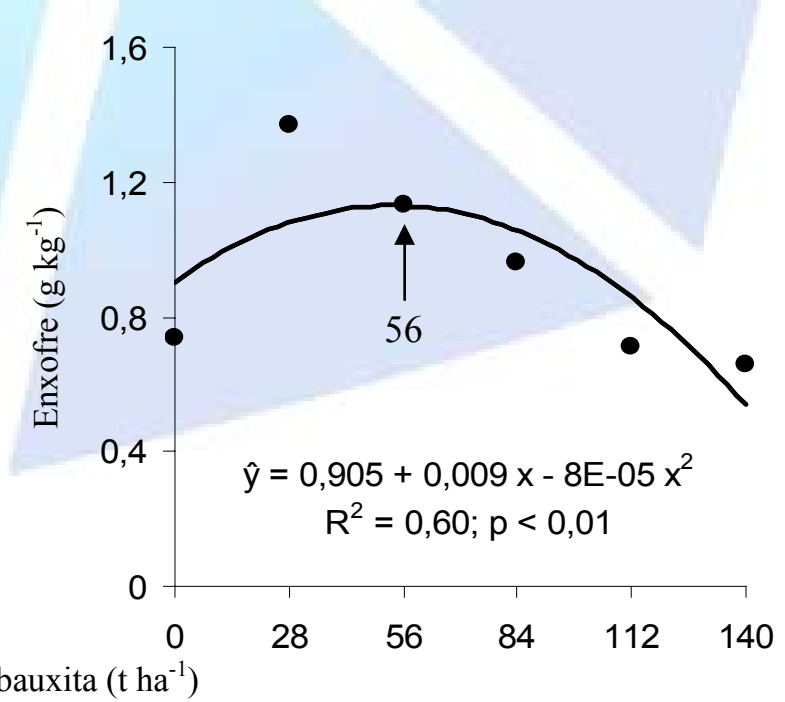

Figura 2. Regressões entre as doses de resíduo de bauxita incorporadas ao solo e o teor de macronutrientes da folha de cana-de-açúcar. 
Com a adição do resíduo de bauxita ao solo houve um acréscimo nos teores de fósforo na folha até a dose de $125 \mathrm{t} \mathrm{ha}^{-1}$, sendo que doses superiores diminuem a absorção desse nutriente pela cultura (Figura 2b). O aumento na absorção de fósforo pode ser explicado pelo aumento da disponibilidade desse nutriente no solo. $\mathrm{O}$ resíduo de bauxita, pobre em fósforo, aumentou a disponibilidade do nutriente no solo em função da elevação do $\mathrm{pH}$. Com o aumento de fósforo nesse solo, a cada incremento do resíduo, maior foi à absorção pela planta. Segundo Raij (1991), o teor de fósforo mínimo adequado na parte colhida da cana-de-açúcar é de $0,08 \mathrm{~g} \mathrm{~kg}^{-1}$, e os teores encontrados neste experimento são bem superiores, mas o excesso de fósforo, segundo o mesmo autor, não provoca desordens nutricionais na planta, já que o "consumo de luxo" é transferido para os polifosfatos e outros fosfatos, sem afetar o crescimento.

A concentração de potássio nas folhas também apresentou comportamento quadrático semelhante ao observado para o fósforo, sendo a maior concentração desse nutriente obtida quando se incorporou $101 \mathrm{t} \mathrm{ha}^{-1}$ do resíduo ao solo (Figura 2c). $\mathrm{O}$ aumento dos teores de potássio na planta em função das doses pode ser explicado pelo mesmo motivo ocorrido com fósforo. $\mathrm{O}$ aumento das doses levou a um aumento de potássio no solo e esse aumento acarretou maior absorção deste por parte da planta. A baixa produção de massa seca devera aumentar os teores de potássio e de outros, pelas suas concentrações na maior massa da planta (Figura 3). Outro motivo está associado à grande quantidade de sódio que competiria com os íons de potássio, por sítios de ligações nos colóides do solo, causando à depleção deste último.

Os teores encontrados de potássio na planta de cana-de-açúcar estão acima dos limites mínimos exigidos para um bom desenvolvimento da planta, sendo o limite mínimo é $1,10 \mathrm{~g} \mathrm{~kg}^{-1}$ para a parte colhida da cana de açúcar (RAIJ 1991).

Os teores de cálcio e magnésio na planta diminuíram linearmente com aquela dose de resíduo de bauxita (Figuras $2 \mathrm{~d}$ e $2 \mathrm{e}$ ). Os íons de cálcio, na solução do solo, podem ser perdidos na água de percolação e serem absorvidos pela planta, serem adsorvidos ao redor de partículas que constituem o complexo coloidal do solo ou tornarem-se insolúveis, como um composto secundário de cálcio. Especificamente neste estudo, a primeira hipótese pode ser descartada. Uma das causas da diminuição da absorção de cálcio pela planta está no aumento de cálcio da solução, fazendo com que o equilíbrio entre solução do solo e complexo coloidal, tenda a deslocar-se para o complexo coloidal, ou seja, algum cálcio passa da solução do solo para a fase sólida, sendo por ele adsorvido (COELHO e VERLENGIA, 1988), explicando, assim, a diminuição dos teores de cálcio em função do aumento das doses. Com o aumento da dose, houve aumento do cálcio disponível no solo (Figura 1d), o que não explica a diminuição dos teores na planta. As doses de cálcio também são altas para prover sua insolubilização e ainda ser disponível. Com essa transformação o cálcio não seria absorvido pela planta (NOBILE, 2005). Contudo, os teores adequados para o cálcio na planta são de 2 a $8 \mathrm{~g} \mathrm{~kg}^{-1}$, e os teores observados mesmo com a diminuição encontram-se dentro dos limites aceitáveis de acordo com Raij et al. (1996). 
Semelhantemente ao cálcio, como era de se esperar, o aumento das doses de resíduo de bauxita diminuíram a quantidade de magnésio absorvido, em função da sua adsorção no solo, formação de compostos ou diminuição do sistema radicular (Figura $2 \mathrm{e})$.

Os níveis adequados de magnésio em plantas, (RAIJ 1991), variam de 2 a 5 g $\mathrm{kg}^{-1}$. As aplicações acima de $56 \mathrm{t} \mathrm{ha}^{-1}$ reduziram esses teores para valores muito baixos. A aplicação de $28 \mathrm{t} \mathrm{ha}^{-1}$, mesmo com a diminuição na absorção pela planta continua dentro da faixa ideal para um bom desenvolvimento.

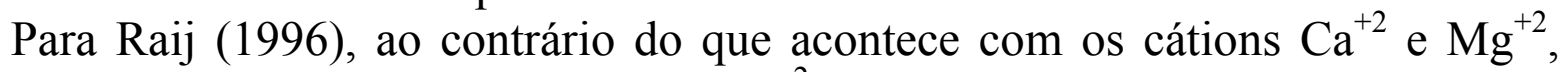
mais retidos na camada arável do solo, $\mathrm{o} \mathrm{SO}_{4}^{-2}$ sofre nessa camada, três fatores que dificultam sua permanência. O primeiro é a presença de matéria orgânica, que reduz a adsorção por óxidos e aumenta a carga negativa do solo, portanto liberando sulfatos para a solução do solo. O segundo é o aumento do $\mathrm{pH}$ e a liberação de sulfatos adsorvidos. Finalmente, os fosfatos aplicados em adubações ocupam preferencialmente as posições de troca que seriam ocupadas por sulfatos.

A elevação do $\mathrm{pH}$, provocada pela adição do resíduo de bauxita (Figura 1a), aumentou os teores de enxofre no solo (Figura 1f) e, consequentemente, fez com que as plantas absorvessem mais enxofre até a dose de $56 \mathrm{t} \mathrm{ha}^{-1}$ de resíduo, a partir da qual o aumento das doses do resíduo proporcionou reduções nos teores de enxofre na planta.

A quantidade de matéria seca produzida é um parâmetro importante para se ter idéia da produção da cultura em relação aos tratamentos testados. A quantidade de massa seca reflete o tratamento que a cultura recebeu, podendo ser maior ou menor em função dos tratos culturais. As doses do resíduo de bauxita incorporadas ao solo proporcionaram um efeito quadrático na produção de massa seca (Figura 3) da canade-açúcar, sendo a máxima produção atingida na dose de $64 \mathrm{tha}^{-1}$ do resíduo incorporado ao solo. A utilização de doses superiores seria prejudicial à produção de massa seca. Provavelmente, a diminuição da massa seca, acima da dose de $64 \mathrm{t} \mathrm{ha}^{-1}$, seja devida à grande quantidade de sódio presente no resíduo, afetando o desenvolvimento radicular e a absorção de água concordando com Bernstein e Hayward (1958) e, consequentemente, prejudicando o crescimento de folhas e colmos. Pearson et al. (1966) e Oliveira (1983), estudando o efeito de sais, também obtiveram decréscimos no peso de matéria seca, estando de acordo com os resultados encontrados neste estudo. 


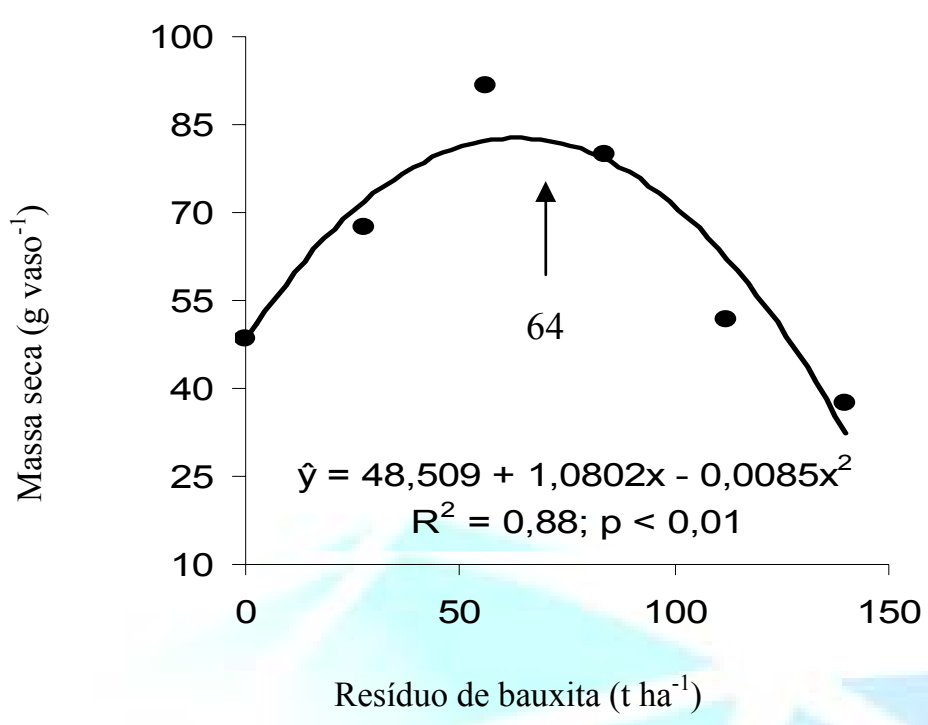

Figura 3. Regressão entre as doses de resíduo de bauxita incorporados ao solo e a produção de matéria seca da cana-de-açúcar.

Portanto, fica demonstrado que a aplicação do resíduo da mineração de bauxita pode ser uma opção interessante para a agricultura, na medida em que fornece nutrientes às plantas e permite destinação técnica aos mesmos, contemplando aspectos relacionados a um menor impacto desse material no ambiente.

\section{CONCLUSÕES}

A incorporação do resíduo de bauxita no solo proporcionou aumento nos teores dos macronutrientes do solo, sendo que apenas para o enxofre doses acima de $83 \mathrm{t} \mathrm{ha}^{-1}$ proporcionaram reduções do nutriente. Já para os teores de macronutrientes determinados na folha, doses acima de 70,$5 ; 125 ; 101 ; 56 \mathrm{t} \mathrm{ha}^{-1}$ diminuiu os teores de nitrogênio, fósforo, potássio e enxofre respectivamente. Para o cálcio e o magnésio a utilização do resíduo proporcionou a diminuição dos seus teores foliares. A dose do resíduo de bauxita na qual houve a maior produção de massa seca da cana-de-açúcar foi de $64 \mathrm{tha}^{-1}$.

\section{REFERÊNCIAS}

Bernstein, L.; HAYWARD, H. E. Physiology of tolerance. A. Rev. Pl. Physiol., Palo Alto, v.9, n.1, p.25-46, 1958. 
COELHO, F.S.; VERLENGIA, F. Fertilidade do Solo. Campinas: Instituto Campineiro de Ensino Agrícola Agronômico, 1988.

FACHINI, M.; GALBIATTI, J. A.; PAVANI, L. C. Níveis de irrigação e de composto de lixo orgânico na formação de mudas cítricas. Engenharia Agrícola, Jaboticabal, v. 24, n. 3, p. 578-588, 2004.

FERREIRA, C.G. Estudos sobre o comportamento de espécies florestais em áreas degradadas pela disposição de resíduo de bauxita através do uso de solo de camada superficial e gesso. 2001. 117 f. Tese (Doutorado em Agronomia) - Centro de Estudos Ambientais, Universidade Estadual Paulista, Rio Claro, 2001.

FORTIN, J.; KARAM, A. Phosphorus sorption by red mud residue as affected by concentration and reaction time. Agrochimica, Quebec, v.45, n.1-2, p.55-66; 2001.

HARTLEY, M.; THORPE, L. Red mud stabilized limestone road base trial. Pinjarra, 1980.

LANARV - LABORATÓRIO NACIONAL DE REFERÊNCIA VEGETAL. Análise de corretivos, fertilizantes e inoculantes: métodos oficiais do Laboratório Nacional de Referência Vegetal. Brasília,1988. 104 p.

MCPHARLIN, I.R; JEFFERY, R.C.; WEISSBERG R. Determination of the residual value of phosphate and soil test phosphorus calibration for carrots on a Karrakatta sand. Commun Soil Sci Plant Anal, 25: 489-500. 1994.

MALAVOLTA, E.; VITTI, G. C.; OLIVEIRA, S.A. Avaliação do Estado Nutricional das Plantas: princípios e aplicações. Piracicaba: POTAFOS, 1997. $319 \mathrm{p}$.

MONTERO, J. I.; CASTILLA, N.; GUTIERREZ de RAVÉ, E; BRETONES, F. Climate under plastic in the Almeria. Acta Horticultural, Leuven, v.170, n. 1, p.227234, 1985.

NOBILE, F. O. de. Efeito da aplicação de resíduo da mineração de bauxita no solo e na planta de cana-de-açúcar. 2005. 117f. Dissertação (Mestrado em Ciência do Solo) - Faculdade de Ciências Agrárias e Veterinárias, Universidade Estadual Paulista, Jaboticabal, 2005.

OLIVEIRA, F.A. Efeito da salinidade de água de irrigação sobre algumas características do solo e da cultura de arroz (Oryza Sativa, L.). 1983. 139 f. 
Dissertação. (Mestrado em Nutrição Mineral de Plantas) - Escola Superior de Agronomia “Luiz de Queiroz", Universidade de São Paulo, Piracicaba, 1983.

PEARSON, G. A.; AYERS, A. D.; EBERHARD, D. L. Relative salt tolerance of rice during germination and early seedling development. Soil sci,, Baltimore, v.103, n.3, p.151-156, 1966.

RAIJ, B. van. Fertilidade do solo e adubação. Piracicaba: Agronômica Ceres, 1991. $343 \mathrm{p}$.

RAIJ, B. van; CANTARELLA, H.; QUAGGIO, J. A.; FURLANI, A. M. C. (Ed.) Recomendações de adubação e calagem para o Estado de São Paulo. $2^{\mathrm{a}}$. Ed. Campinas: Instituto Agronômico de Campinas, 1996. p. 39. (Boletim Técnico 100).

ROBERTSON, W.J.; JEFFERY, R.C.; MCPHARLIN, I.R. Residues from bauxitemining (red mud) increase phosphorus retention of a Joel sand without reducing yield of carrots. Australia. Communications in Soil Science and Plant Analysis. v. 28, n. 13-14, p. 1059-1079; 1997.

SAS INSTITUTE. SAS user's guide. Cary, 1999. 595 p.

SOUZA, H. R. de. Aproveitamento de lama vermelha para produção de agregado para a construção civil. In: do Ó, O.M.P. coord. Recuperação de Rejeitos da Indústria Metalúrgica. Associação Brasileira de Metais. Volta Redonda, p.81-92, 1989.

SUMMERS, R. N.; SMIRK, D. D.; KARAFILIS, D. Phosphorus retention and leachiest from sandy soil amended with bauxite residue (red mud). Australian Journal of Soil Research. v. 34, n. 4, p. 555-567, 1996.

WARD, S. C. The use of the fine residue from bauxite refining as a soil amendement. 1986. $318 \mathrm{f}$. Tese (PhD em Environmental and Life Science) Murdoch University, Western Australia, 1986.

WONG, J. W. C. Sodium release characteristics in revegetation of fine residue bauxite refining residue (red mud). 1990. $443 \mathrm{f}$. Tese (PhD em Environmental and Life Science) - Murdoch University, Western Australia, 1990. 